\title{
Proceeding
}

Supplementary Issue: Winter Conferences of Sports Science. Costa Blanca Sports Science Events, 22-23 March 2021. Alicante, Spain.

\section{Measuring some kinesthetic perception tests using the computer-programmed atrussonic distance sensor for volleyball players according to their specialities}

\author{
MOHAMMED RAHIM FAIL $\triangle$, RAJA ABDULSAMAD ASHOOR, WATHIQ ABDULSAHIB OUBED \\ College of Physical Education and Sports Sciences, Basra University, Iraq
}

\begin{abstract}
The problem of the research lies in the possibility of making the tests used through accurate devices that work according to the computer system to avoid self-evaluation, which takes a lot of time in the testing process, the study aimed to design some tests of kinaesthetic perception using the computer-programmed atrousonic distance sensor and identify the level of some kinaesthetic perception tests For the research sample, the research sample was represented by a group of volleyball players in (Basra, Maysan, Dhi Qar), totalling (40) players divided according to their specializations in playing. The results of the Colum grove Seminarov test for the normal distribution of volleyball players according to their specialities as well as the results of the analysis of variance of the value of $(F)$ The calculated and tabular tests for the perception of the distance for the right hand and the perception of the distance for the left hand of the volleyball players, the researchers concluded that there are differences between the specialities of playing in the volleyball team and this is evidence that the specifications of the volleyball players differ from one player to another according to the requirements of modern play. Researching the reasons that cause the variation in the level of some specialities of playing in the volleyball team.
\end{abstract}

Keywords: Kinaesthetic; Computer; Programmed distance; Atrussonic distance.

Cite this article as:

Fail, M.R., Ashoor, R.A., \& Oubed, W.A. (2021). Measuring some kinesthetic perception tests using the computer-programmed atrussonic distance sensor for volleyball players according to their specialities. Journal of Human Sport and Exercise, 16(3proc), S1450-S1456. https://doi.org/10.14198/jhse.2021.16.Proc3.61

Corresponding author. College of Physical Education and Sports Sciences, Basra University, Iraq.

E-mail: mohammedfaeel2016@gmail.com

Abstract submitted to: Winter Conferences of Sports Science. Costa Blanca Sports Science Events, 22-23 March 2021. Alicante, Spain.

JOURNAL OF HUMAN SPORT \& EXERCISE ISSN 1988-5202.

(c) Faculty of Education. University of Alicante.

doi:10.14198/jhse.2021.16.Proc3.61 


\title{
INTRODUCTION
}

The method of measurement may differ, including direct measurements, such as measuring length with a tape measure or measuring weight with a scale device, and it gives accurate measurements, and there is an indirect measurement method, such as estimating the speed of a ball or evaluating the performance of a skill. Here, four evaluators do not agree on the same degree, which is a subjective measurement, which is an evaluation that is affected by factors Some of them are psychological, including the experience factor, which leads to bias, which generates a lack of sincerity in the measurement, that is, the measured characteristic is of an inaccurate level, and this is what Rajaa Abdul Samad (2008) confirmed on the contrary if the measurement was done using a device connected to an electronic circuit linked to a computer where The variables to be measured are carefully sensed and transferred directly to the computer, and stored and retrieved statistically whenever they are wanted.

The possibility of making the tests used through accurate devices that work according to the computer system to avoid self-evaluation, which takes a lot of time in the testing process, and the research problem appears clearly by making eleven tests to be tested through One device is different from the place where it is placed in the test site, the goal of that is accurate in measuring and storing data of different types and indexing in displaying data on what the researcher wants to obtain the gender of males or females or both easily and conduct statistical treatments with full transparency through ready-made tables and the application of statistical laws in An excel file or transferring it to SPSS, and the test of eleven tests can be tested all or choose a section of them, which generates saving in effort and time and shortens time, and obtaining immediate results gives an incentive to all testers.

\section{OBJECTIVES}

- Designing some kinaesthetic perception tests by using the computer-programmed ultrasonic distance sensor.

- Knowing the level of some kinaesthetic perception tests of the research sample.

- Identify the differences in the level of some kinaesthetic perception tests between volleyball players.

\section{Research field}

- The human field: represented by the volleyball players of the Sports Talent Care Department (Basra, Maysan, Dhi Qar).

- Time range: represented by the time from 1/10/2019 to 12/25/2019.

- Spatial field: volleyball courts in (Basra, Maysan, Dhi Qar).

\section{METHODOLOGY}

The researchers used the descriptive approach to suit the nature of the research and its objectives, as it gives a picture of the current reality, develops indicators and builds future predictions.

\section{Sample}

The research eye was represented by a group of volleyball players in (Basra, Maysan, Dhi Qar) and totalling (40) players divided according to their specializations in playing as follows: (7) Libero (8) fast (12) high (13).

\section{Tools and devices used}

\author{
1. A laptop computer.
}


2. A program (Raja test to measure some motor sense-perception tests).

\section{The tests that are measured}

1. Test the maximum strength of the legs by horizontal jumping of the legs.

2. The strength perception test for $50 \%$ of the maximum strength of the two legs, the horizontal jump of the two legs.

3. The test of the maximum strength of the arms by throwing a medical ball weighing $2 \mathrm{~kg}$.

4. The strength perception test of $50 \%$ of the maximum strength of the arms by throwing a medical ball weighing $2 \mathrm{~kg}$.

5. The maximum strength test of the legs on the right side.

6. The strength perception test of $50 \%$ of the maximum strength of the legs on the right side.

7. The maximum strength test of the legs for the left side.

8. The strength perception test of $50 \%$ of the maximum strength of the legs on the left side.

9. The distance perception test for the right hand.

10. Test Distance perception of the left hand.

11. Distance perception test for the two legs.

\section{The test used}

The technology of the gearbox distance sensor is used, which is linked to the Arduino circuit programmed with the computer, and it is a special program created in the Java language by the programmer's expert.

\section{Test name: Rajaa test to measure kinaesthetic perception}

- The purpose of the test: To measure some kinaesthetic perception tests.

- The tools used: 1- An electronic circuit (Arduino - which is a group of electronic circuits compressed in one circuit and can connect any sensors) connected to the computer by a wire as in Figure 1. 2A special program created in the Java language by the expert programmer (Ali Raad) 3- A tape measure $3 \mathrm{~m} 4$ - eye ring 5 - A ruler $10 \mathrm{~cm}$ in width and $50 \mathrm{~cm}$ in length with a thickness of $2 \mathrm{~mm}$.

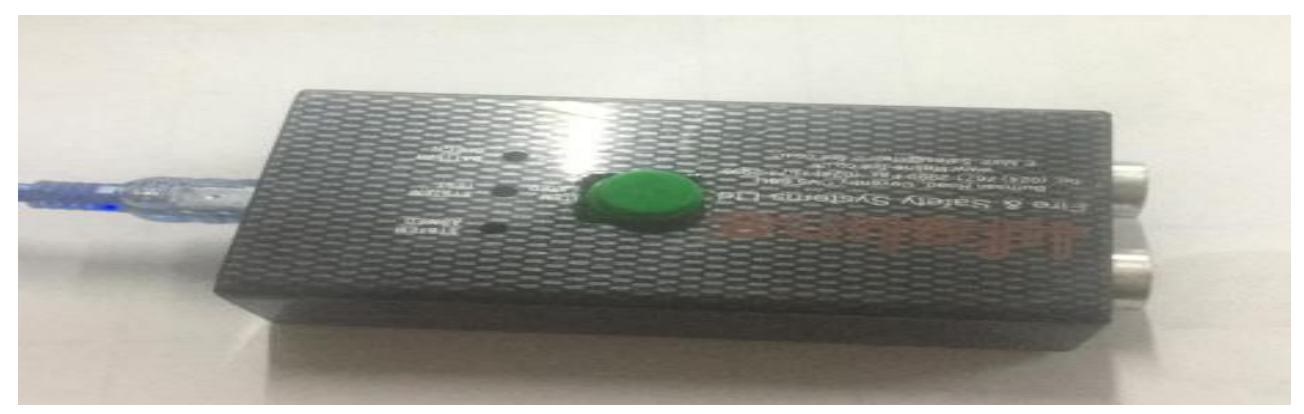

Figure 1. Represents the distance measuring device.

- Method of performance: After running the test through the icon on the desktop, the first window appears in Figure (2). Important data, which must be entered, is entered so that the test does not run, meaning it does not go to the next window unless all the data is entered.

When you press the button to start the test, the third window appears in Figure (3), and when you press the button to display data, the eighth window appears in Figure (8). When you press the Exit button, the program is closed and the program exits, and when the test start button is selected, the third window appears in Figure (3), which The test type is chosen. 


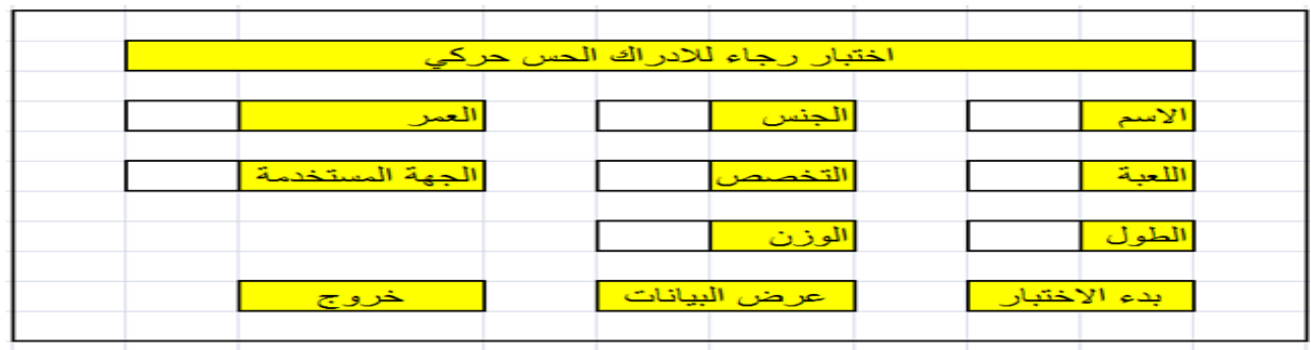

Figure 2. Shows the main test window.

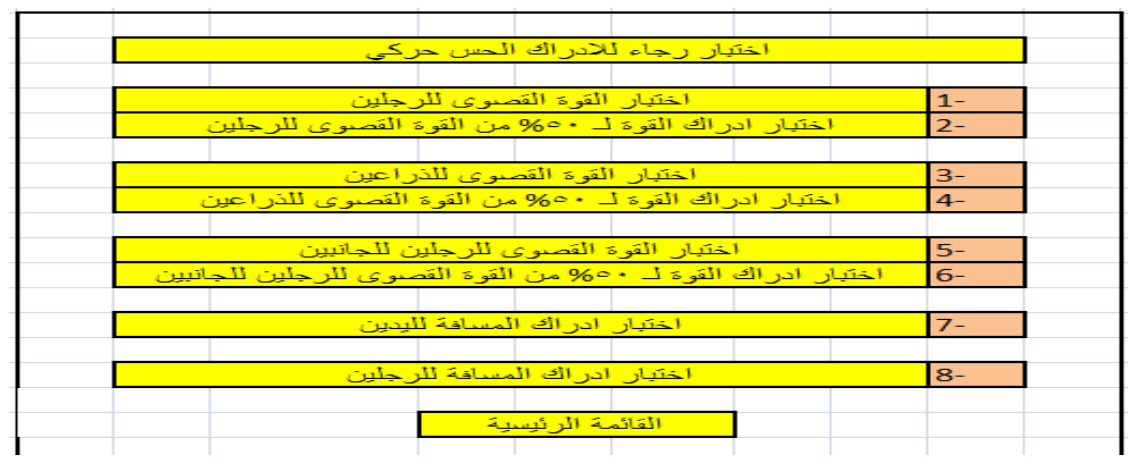

Figure 3. Shows the next window for choosing the test type.

First: After pressing the Save Data button, the window appears, Figure (3), to choose another test, where when you press the Test button (7), the distance perception test for the hands, where the window appears Figure 10, the player sits on a chair against a chair whose length is not less than 1 meter. After trying the test By the player, that is, placing his hand in front of the distance sensor in the device, so the amount of distance appears in front of him on the computer screen, and thus he gets a visualization of the testing mechanism, where through the window 4 Figure (4) and when pressing the perception button a distance of $10 \mathrm{~cm}$ and the eyes are blindfolded, the player must put His hand is at the distance to be perceived, and when you press the device button, the test calculates the exact distance to the nearest centimetre and also calculates directly the difference. Move to the check window (3). If you want to test another player, you must choose the main menu to record new player data and complete the tests, as previously mentioned.

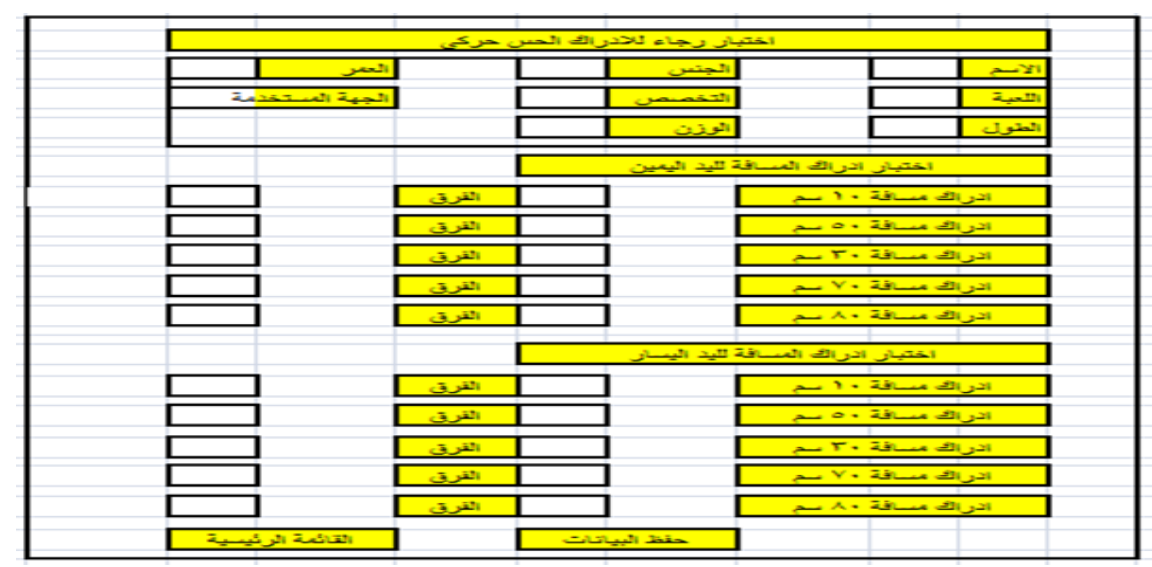

Figure 4. Shows test data. 


\section{The main experience}

The experiment was conducted from $11 / 11 / 2019$ to $11 / 8 / 2019$ on a sample of volleyball players (Basra, Maysan, Dhi Qar).

\section{The statistical means used}

The researchers used the statistical program SPSS version 14.

\section{RESULTS AND DISCUSSIONS}

Table 1. Shows the results of the Colum grove Seminarov test for the normal distribution of volleyball players (a prepared player).

\begin{tabular}{lcccccc}
\hline \multirow{2}{*}{ A prepared player } & \multicolumn{3}{c}{ Kolmogorov-Smirnov(a) } & \multicolumn{3}{c}{ Shapiro-Wilk } \\
\cline { 2 - 7 } & Statistic & df & Sig. & Statistic & df & Sig. \\
\hline Age & 0.173 & 7 & $0.200\left(^{*}\right)$ & 0.922 & 7 & 0.482 \\
Length & 0.245 & 7 & $0.20\left(^{*}\right)$ & 0.898 & 7 & 0.319 \\
the weight & 0.251 & 7 & $0.200\left(^{*}\right)$ & 0.869 & 7 & 0.182 \\
Broad jump & 0.205 & 7 & $0.200\left(^{*}\right)$ & 0.963 & 7 & 0.843 \\
Realizing the wide jump & 0.255 & 7 & 0.186 & 0.871 & 7 & 0.190 \\
Side bounce to the right & 0.185 & 7 & $0.200\left(^{*}\right)$ & 0.967 & 7 & 0.877 \\
Realize the right side jump & 0.242 & 7 & $0.200\left(^{*}\right)$ & 0.854 & 7 & 0.134 \\
Left side jump & 0.262 & 7 & 0.158 & 0.807 & 7 & 0.048 \\
Realizing the left side jump & 0.156 & 7 & $0.200\left(^{*}\right)$ & 0.956 & 7 & 0.788 \\
Medicine throw ball & 0.154 & 7 & $0.200\left(^{*}\right)$ & 0.970 & 7 & 0.901 \\
Realization of throwing a medicine ball & 0.284 & 7 & 0.091 & 0.809 & 7 & 0.050 \\
Right-hand space perception test & 0.162 & 7 & $0.200\left(^{*}\right)$ & 0.972 & 7 & 0.916 \\
Left Hand Distance Perception Test & 0.270 & 7 & 0.132 & 0.842 & 7 & 0.104 \\
Distance perception test for the legs & 0.230 & 7 & $0.200\left(^{*}\right)$ & 0.910 & 7 & 0.394 \\
\hline
\end{tabular}

It is evident from Table (1) that all sig values in (Kolmogorov-Smirnov (a)) are greater than (0.05) and this indicates that the test variables were normally distributed, and this indicates that the test has achieved the purpose of its design to measure a natural characteristic. It concerns players as the natural attributes, including mental abilities, were concentrated in the middle of the values and decreased at the edges of the curve, and this was identical to the sense-kinaesthetic perception test.

Table 2. Shows the results of the analysis of variance of the calculated and tabular (F) value of the two tests of perceiving distance to the right hand.

\begin{tabular}{|c|c|c|c|c|c|c|c|c|}
\hline \multirow{4}{*}{$\begin{array}{l}\text { Right-hand } \\
\text { space } \\
\text { perception } \\
\text { test }\end{array}$} & $\begin{array}{l}\text { Source of } \\
\text { Variation }\end{array}$ & $\begin{array}{l}\text { Some of the } \\
\text { Squares of } \\
\text { the deviations }\end{array}$ & df & MS & $F$ & $p$-value & F crit & $\begin{array}{c}\text { Statistical } \\
\text { Significance }\end{array}$ \\
\hline & Between Groups & 4.4898 & 3 & 1.4966 & \multirow{3}{*}{1.089146} & \multirow{3}{*}{0.3661} & \multirow{3}{*}{2.8663} & \multirow{3}{*}{ Sig. } \\
\hline & Within Groups & 49.4678 & 36 & 1.3741 & & & & \\
\hline & Total & 53.9576 & 39 & & & & & \\
\hline \multirow{3}{*}{$\begin{array}{l}\text { Left-hand } \\
\text { distance } \\
\text { perception } \\
\text { test }\end{array}$} & Between Groups & 16631.47 & 23.6599 & 3 & \multirow{3}{*}{$\begin{array}{l}7.886663 \\
2.599677\end{array}$} & \multirow{3}{*}{3.0337} & \multirow{3}{*}{0.0416} & \multirow{3}{*}{ Sig. } \\
\hline & Within Groups & 3494.268 & 93.5883 & 36 & & & & \\
\hline & Total & 20125.74 & 117.248 & 39 & & & & \\
\hline
\end{tabular}


It is evident from Table (2) to test the distance to the right hand that the tabular value of (F) of ((1.089146), which is greater than the value of $(F)$ calculated, which is (2.866265557), and this indicates the existence of differences between volleyball players (prepared, free, fast and high), as well as for the left hand, therefore, we resort to the test of the least significant difference (LSD) to know which speciality is superior to the other.

Table 3. Shows the differences between the averages and the value of the least significant difference.

\begin{tabular}{|c|c|c|c|c|c|}
\hline \multirow{19}{*}{$\begin{array}{l}\text { Right- } \\
\text { hand } \\
\text { space } \\
\text { perception } \\
\text { test }\end{array}$} & \multicolumn{2}{|c|}{ Differences between the averages } & \multirow[t]{2}{*}{ Difference value } & \multirow[t]{2}{*}{ value LSD } & \multirow[t]{2}{*}{ Indication } \\
\hline & A prepared player & libro & & & \\
\hline & 3.993 & 4.874 & \multirow{2}{*}{\begin{tabular}{|l|}
0.576 \\
\end{tabular}} & \multirow{17}{*}{1.458} & \multirow{2}{*}{ Sig. } \\
\hline & \multicolumn{2}{|l|}{0.882} & & & \\
\hline & A prepared player & Rapid & & & \\
\hline & 3.993 & 4.510 & 0.940 & & \multirow{2}{*}{ Sig. } \\
\hline & \multicolumn{2}{|l|}{0.517} & & & \\
\hline & A prepared player & Higher & & & \\
\hline & & 3.987 & 1.452 & & \multirow{2}{*}{ Sig. } \\
\hline & \multicolumn{2}{|l|}{$\begin{array}{l}3.993 \\
0.006\end{array}$} & & & \\
\hline & \multicolumn{2}{|l|}{ libro } & & & \multirow{3}{*}{ Sig. } \\
\hline & 4.874 & 4.510 & 1.093 & & \\
\hline & \multicolumn{2}{|l|}{0.364} & & & \\
\hline & libro & Higher & & & \\
\hline & 4.874 & 3.987 & 0.570 & & \multirow{2}{*}{ Sig. } \\
\hline & \multicolumn{2}{|l|}{0.888} & & & \\
\hline & Rapid & Higher & & & \\
\hline & 4.510 & 3.987 & & & \multirow[b]{2}{*}{ Sig. } \\
\hline & \multicolumn{2}{|l|}{0.523} & 0.934 & & \\
\hline \multirow{18}{*}{$\begin{array}{l}\text { Left Hand } \\
\text { Distance } \\
\text { Perception } \\
\text { Test }\end{array}$} & A prepared player & libro & & \multirow{18}{*}{1.458} & \multirow{3}{*}{ Sig. } \\
\hline & 3.519 & 4.615 & & & \\
\hline & \multicolumn{2}{|l|}{1.096} & 0.362 & & \\
\hline & A prepared player & Rapid & & & \\
\hline & 3.519 & 5.384 & 0.408 & & \multirow{2}{*}{ Sig. } \\
\hline & \multicolumn{2}{|l|}{1.865} & & & \\
\hline & A prepared player & Higher & & & \\
\hline & 3.519 & 5.758 & 0.781 & & \multirow{2}{*}{ Sig. } \\
\hline & \multicolumn{2}{|l|}{2.239} & & & \\
\hline & libro & Rapid & & & \\
\hline & 4.615 & 5.384 & 3.927 & & $\mathrm{Nh}$ sia \\
\hline & -0.769 & & & & No sig. \\
\hline & libro & Higher & & & \\
\hline & 4.615 & 5.758 & 4.300 & & \\
\hline & 1.143 & & & & No sig. \\
\hline & Rapid & Higher & & & \\
\hline & 5.384 & 5.758 & & & \\
\hline & 0.374 & & 1.084 & & sig. \\
\hline
\end{tabular}

It is evident from Table (3) that the odds are for the player prepared at the expense of the rest of the players (free, fast and high) in the designed test and that the prepared player is most of his daily exercises on the 
process of accuracy in perceiving distance, as he is responsible for the success in delivering the ball at different heights and specific places according to Multiple play situations, which requires privacy during training and training, also, to be working with both the left and right hands during periods of play at a very high rate, the prepared player is the key to the team to get the point and whenever the numbers are correct and proficient whenever they perform To the success of the attack process of all kinds, while the values of the (high) hitter player were superior to the players (free and fast) in the designed test. The researchers attribute that to the fact that the responsibility placed on the high hitting player necessitated that he attacks in multiple ways and heights and different places from above. The net is like the short and long balls (close to the air sticks) as well as the medium height and high balls, which usually make him aware of the time and distance of each type of balls and has to master the appropriate timing with the start and so on Promoting the ball from the hand of the prepared player, Kinetic performance and skilful achievement depend largely on sensory information in which the sensory input is organized and translated (perception, kinaesthetic) and this comes in line with the importance of skill performance through a sense of distance and time.

\section{CONCLUSIONS}

1. That all members of the sample were distributed naturally.

2. The research that is used in its field procedures, such as the standardized test using electronic technology in calculating the score, results in ease in obtaining the degree, shortening the time and a lack of requirements for research in addition to the lack of auxiliary staff.

3. The use of programming in the creation Tests such as the use of the distance measurement sensor (Atrussonic) and linking it to (Arduino) is a compact and highly useful method in terms of accuracy in measurement and ease of storing data.

\section{REFERENCES}

Adel Majeed. (2009). Evaluation of some indicators of anoxic capacity according to the specializations of volleyball players in Basra Governorate, research published in the First Scientific Conference on Training and Physical Physiology.

Ali Raad Al-Tamari. (2015). Program Expert, MSc, Computer Science, University of Malaysia, 2015.

Ikhlas Abdel Hafeez and Mustafa Hussein. (2002). Scientific Research Methods and Statistical Analysis in the Educational, Psychological and Mathematical Fields, Cairo, Al-Kitab Center for Publishing, 2002.

Muhammad Sami. (2000). Measurement and Evaluation in Education and Psychology, Amman, House of Biography for Publishing and Distribution.

Nahida Abdel Zaid and others. (2015). modern volleyball and its specialized requirements, Lebanon, Beirut, Dar Al-Kutub Al-IImiyya.

Rajaa Abd Al-Samad. (2008). Designing and Standardizing Tests to Measure Short-Term Memory and Compound Motor Response Velocity, Master Thesis, Basra University, College of Physical Education.

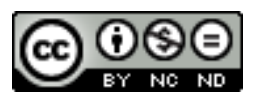

This work is licensed under a Attribution-NonCommercial-NoDerivatives 4.0 International (CC BY-NC-ND 4.0). 